This item was submitted to Loughborough's Research Repository by the author.

Items in Figshare are protected by copyright, with all rights reserved, unless otherwise indicated.

\title{
Exploring the impact of workplace cyberbullying on trainee doctors
}

PLEASE CITE THE PUBLISHED VERSION

https://doi.org/10.1111/medu.12666

PUBLISHER

John Wiley \& Sons Ltd

VERSION

AM (Accepted Manuscript)

\section{PUBLISHER STATEMENT}

This work is made available according to the conditions of the Creative Commons Attribution-NonCommercialNoDerivatives 4.0 International (CC BY-NC-ND 4.0) licence. Full details of this licence are available at: https://creativecommons.org/licenses/by-nc-nd/4.0/

\section{LICENCE}

CC BY-NC-ND 4.0

\section{REPOSITORY RECORD}

Farley, Samuel, lain Coyne, Christine A. Sprigg, Carolyn Axtell, and Ganesh Subramanian. 2015. "Exploring the Impact of Workplace Cyberbullying on Trainee Doctors". Loughborough University.

https://hdl.handle.net/2134/20812. 


\title{
Exploring the impact of workplace cyberbullying on trainee doctors
}

\author{
Farley, $\mathrm{S}^{1}$; Coyne, $\mathrm{I}^{2}$; Sprigg, $\mathrm{C}^{1}$; Axtell, $\mathrm{C}^{1}$; Subramanian, $\mathrm{G}^{3}$ \\ ${ }^{1}$ Sheffield University Management School \\ ${ }^{2}$ University of Nottingham \\ ${ }^{3}$ Nottingham University Hospitals NHS Trust
}


Objectives: Workplace bullying is an occupational hazard for trainee doctors. However little is known about their experiences of cyberbullying at work. This study examines the impact of cyberbullying among trainee doctors, and how attributions of blame for cyberbullying influenced individual and work-related outcomes.

Methods: Doctors more than six months into their training were asked to complete an online survey that included measures of cyberbullying, blame attribution, negative emotion, job satisfaction, interactional justice and mental strain. In total, 158 trainee doctors (104 females, 54 males) completed the survey.

Results: Overall, 71 (45\%) respondents experienced at least one act of cyberbullying. Cyberbullying adversely impacted on job satisfaction $(\beta=-0.19 ; \mathrm{P}<.05)$ and mental strain $(\beta=0.22 ; P<.001)$, although attributions of blame for the cyberbullying influenced its impact and the mediation path. Negative emotion mediated the relationship between self-blame for a cyberbullying act and mental strain; whereas interactional injustice mediated the association between blaming the perpetrator and job dissatisfaction.

Conclusions: Cyberbullying acts were experienced by nearly half of the sample during their training and were found to significantly relate to ill-health and job dissatisfaction. The deleterious impact of cyberbullying can be addressed through both workplace policies and training for trainee doctors and other experienced medical professionals. 


\section{Introduction}

During the past fifteen years research on workplace bullying has spread from origins in Scandinavia across Europe and beyond ${ }^{1}$. Within this global research base, evidence suggests that bullying occurs more in some occupational sectors than others, with studies identifying higher levels of bullying in the health sector ${ }^{2,3}$, particularly among trainee doctors ${ }^{4,5}$. Recent research has revealed that trainee doctors are engaging with various forms of technology in relation to their work ${ }^{6,7}$. Given this context, the current paper considers the extent that trainee doctors' experience bullying through technology, otherwise known as cyberbullying.

Cyberbullying research has typically been conducted in school settings; with limited research conducted among working populations ${ }^{8,9}$ and much atheoretical in nature. Cyberbullying has been defined as "an aggressive, intentional act carried out by a group or individual, using electronic forms of contact, repeatedly and over time against a victim who cannot easily defend him or herself ${ }^{\prime 10}$ (p.376). It can occur at any time or place ${ }^{11}$, some perpetrators can remain anonymous ${ }^{12}$ and there is a permanence associated with certain cyber acts. Given the nature of cyberbullying, it has been suggested that it exerts a stronger impact on targets than offline bullying ${ }^{13}$. We are unaware of previous research which has examined the impact of cyberbullying on trainee doctors. Our research therefore uses two theoretical frameworks to help theorise how cyberbullying influences individual and work-related outcomes.

Firstly, dysempowerment theory ${ }^{14}$ states that when a negative workplace event is perceived by the victim as violating their dignity, it triggers a negative affective reaction which influences attitudes and well-being. Dysempowerment theory can therefore aid our understanding of how cyberbullying might produce negative outcomes as it can violate dignity and norms of respect - resulting in a strong dysempowerment process. However the theory does not illustrate how individuals arrive at the conclusion regarding who to blame for polluting acts, nor how blame attributions influence perceptions of whether ones dignity has 
been violated. The extent to which an event is dysempowering may depend on how blame for that event is attributed. We therefore extend dysempowerment theory by using the attributional model of workplace harassment ${ }^{15}$.

The attributional model of workplace harassment ${ }^{15}$ proposes that the way victims attribute blame for harassment influences how fairly they perceive their work situation, and subsequent well-being, attitudes and behaviours. Specifically, when individuals blame themselves for being harassed, they experience reduced well-being. This proposition is based on the notion that internalising a negative event will result in greater negative affect, which in turn causes ill-health ${ }^{16,17}$. When an individual blames him/herself for experiencing harassment they are unlikely to perceive that their dignity has been violated as they may feel that they deserved negative treatment. However dysempowerment may still occur, because attributing blame for negative events internally has been linked to negative emotions including shame ${ }^{18}$ and guilt ${ }^{19}$, which may produce detrimental outcomes.

In contrast, when individuals blame the perpetrator for harassment a perception that one's dignity has been violated is hypothesised to occur. Here we conceptualise dignity as interactional justice, which refers to the quality of interpersonal treatment, including the extent that individuals feel that they are treated with dignity, respect, truthfulness and propriety $^{20}$. Empirical evidence indicates that individuals who attribute blame for harassment externally are less likely to experience psychological ill-health than those who attribute blame internally ${ }^{21}$. Yet, research has linked interactional injustice to lower job satisfaction, life satisfaction and organisational commitment ${ }^{22}$. Thus blaming the perpetrator may act as a separate route to dysempowerment (see figure 1).

Insert Figure 1 here 
This study addresses the following key questions. How prevalent is cyberbullying among trainee doctors? What is the impact of workplace cyberbullying and does this vary according to how trainee doctors place the blame for their cyberbullying experiences? 


\section{Method}

\section{Design and Procedure}

The respondents were first year trainee doctors (who were more than six months into their training) and second year trainee doctors on the foundation programme. The aim of the foundation programme is to 'provide broad clinical experience with a focus on acute care' ${ }^{23}$. A competency based curriculum prescribes learning and development in such areas as professionalism, safety, ethical and legal issues and patient relationships ${ }^{24}$. Data was gathered using an online self-report survey which was distributed by foundation programme management to trainee doctors across eight different UK NHS Trusts, via a link embedded in an email. The survey included an information page and participants were given the option to withdraw by closing down the survey. No incentive was offered for survey completion and it was sent to 1996 trainee doctors in total. The final sample consisted of 158 respondents, 104 females $(66 \%)$ and 54 males $(34 \%)$, with a mean age was 27 years $(S D=4.79)$. The response rate of $7.9 \%$ is low, although this was expected due to the sensitive nature of the study. For instance, research on workplace cyberbullying in the Australian manufacturing sector reported a similar response rate of $7.3 \%{ }^{25}$. Furthermore, the gender split of the sample is comparable to gender split data of the trainee doctor population in 24 of the 25 foundation schools, which was reported as $59.8 \%$ female (F1 programme) and $58.9 \%$ female (F2 programme) in $2013^{26}$. Ethical approval was obtained from Sheffield University Management School and the University of Nottingham.

\section{Study Measures}

All variable measures were included in the online survey and participants navigated through the survey web pages using a 'next' button. The validated and reliable cyber negative acts questionnaire (CNAQ) $)^{9}$ was used to measure cyberbullying. The CNAQ is an adapted version 
of the negative acts questionnaire revised (NAQr) ${ }^{27}$, used to measure workplace cyberbullying behaviours. Respondents were asked how often they had experienced 19 bullying behaviours through eight forms of technology (1. text messaging, 2. pictures/photos or video clips, 3. phone calls, 4. email, 5. chat rooms, 6 . instant messaging 7. websites, 8. social networking websites). An example item was: 'Hints or signals from others that you should quit your job'. The five-point response scale was: 'never', 'now or then', 'monthly', 'weekly' and 'daily'. An alpha coefficient of 0.85 was obtained from the sample. Respondents were given the option of reporting who perpetrated the majority of the cyberbullying (e.g. managers, consultants, other trainees, nurses, patients of relatives, other).

Blame attribution was measured using items adapted from internationally recognised research ${ }^{21,28}$. After reporting their experience of cyberbullying behaviours, respondents were asked to rate the extent to which they agreed with the following statements: "I am partly to blame for this behaviour towards me" (self-blame) and "The perpetrator is to blame for this behaviour towards me" (perpetrator-blame). The word 'partly' was used in the selfattribution item as it has been suggested that this reduces the probability of ego-defensive responding ${ }^{17}$.

State negative affect was measured using the 10 -item NA scale of the PANAS scales ${ }^{29}$, which measures the degree to which an individual is generally feeling upset or unpleasantly aroused. The PANAS is a widely used, validated measure that has evidence of reliability ${ }^{30}$. Respondents were asked to state the extent they had felt a particular emotion over the last two weeks, such as being ashamed, hostile, jittery, or scared. Response categories were: 'very slightly', 'a little', 'moderately', 'quite a bit', and 'extremely.' An alpha coefficient of 0.92 was obtained in the current study.

Interpersonal justice was measured with a three item scale developed by Bies and Moag ${ }^{20}$ which measures the extent that participants felt treated with dignity and respect at work. A 
sample item was: "At work I am treated with dignity". The response categories were: 'very slightly' or 'not at all', 'a little', 'moderately', 'quite a bit' and, 'extremely.' The alpha level in the current study was 0.95 .

Job satisfaction was assessed using a single-item measure ${ }^{31}$ that has been extensively applied and published in prominent journals ${ }^{32}$. Respondents were asked "Overall, how satisfied are you with your job?" The response category was: 'very dissatisfied', 'dissatisfied', 'neutral', 'satisfied', and 'very satisfied'.

Mental strain was assessed with the 12 -item General Health Questionnaire (GHQ-12) ${ }^{33}$ which assesses general mental health or psychological distress. Each item assesses symptoms of general mental strain over the past few weeks, with higher scores representing more strain. Internal consistency was shown to be high in this sample (Alpha $=0.90)$

\section{Control Variables}

Several control variables were used (age, gender and general job stress) to assess whether cyberbullying had a unique relationship with the outcome variables. General job stress was assessed using the seven-item 'Pressure' subscale of the 'Stress in General' (SIG) scale ${ }^{34}$ (Alpha $=0.89$ in this sample). This scale assesses general perceived strain, rather than strain that is tied to a specific stressor. Participants were asked to respond to seven adjectives that could describe their job, including "demanding", "pressured" and "calm". The response categories were 'yes', 'no' and 'unsure'. 


\section{Results}

Parametric methods were used to analyse the data. It has been suggested that parametric statistics cannot be applied to ordinal, Likert scale data ${ }^{35}$ because this data reflects qualitative statements and therefore the gaps between intervals cannot be assumed as equal. However, researchers defending the use of parametric techniques on ordinal data argue that Likert scales involving sums across items are likely to be ordinal, and parametric techniques have been shown to be robust, even when data is skewed and not normally distributed ${ }^{\text {Error! Bookmark }}$ not defined.,36. As such, parametric tests are appropriate to analyse the current data.

\section{Prevalence}

Seventy one respondents (45\%) had experienced at least one cyberbullying act, with fellow trainees reported as the main perpetrators $(31.7 \%=21$ respondents). Other than trainees, $24.4 \%(20)$ of respondents cited consultants as the perpetrator, $19.5 \%$ (16) cited an unspecified source, $18.3 \%(15)$ reported managers, $3.7 \%(3)$ reported nurses and $2.4 \%(2)$ reported patients or relatives as responsible.

Cyberbullying was significantly negatively correlated with job satisfaction $(r=-.29)$ and significantly positively correlated with mental strain $(r=.36)$. Hierarchical regression analysis confirmed these relationships between the variables whilst controlling for age, gender and general job stress (see Table 1).

Insert Table 1 here

To examine mediation effects, bootstrapping procedures were adopted with accelerated estimates based on 5000 re-samples and $95 \%$ confidence intervals (BCas) ${ }^{37}$. Bootstrapping has higher power and control over Type 1 errors than the Baron and Kenny ${ }^{38}$ and Sobel ${ }^{39}$ methods. Point estimates of indirect effects are considered significant when zero is not contained in the 95 per cent confidence intervals ${ }^{40}$. Kappa-squared (the proportion of the 
total effect shown by a sample) was used to assess the effect size of the mediation relationships. A Kappa-squared value of .01 is considered small, values near .09 are medium and values around .25 represent a large effect ${ }^{41}$.

Analysis of the impact of cyberbullying on mental strain and job satisfaction found that negative affect showed a large mediation effect in the relationship between cyberbullying and mental strain $\left(\mathrm{K}^{2}=.28\right)$. Comparatively, interactional injustice mediated the cyberbullying job satisfaction relationship $\left(\mathrm{K}^{2}=.19\right)$ (Table 2$)$. The indirect effect of interactional injustice on mental strain and negative affect on job satisfaction were tested, although these relationships were shown to be non-significant (Table 2). This suggests that cyberbullying exerts an effect on each outcome via separate routes.

Regarding the path between cyberbullying and mental strain, it was hypothesised that selfblame would mediate the relationship between cyberbullying and negative affect (Figure 1). Furthermore, it was hypothesised that negative affect would mediate the relationship between self-blame and mental strain. Support was only found for the latter hypothesis, which suggests that when trainee doctors blame themselves for experiencing cyberbullying, a negative affective reaction occurs which may lead to mental strain $\left(K^{2}=.27\right)$.

Analysis supported the hypotheses of perpetrator blame mediating the cyberbullying and interactional injustice relationship $\left(\mathrm{K}^{2}=.07\right)$; and interactional injustice mediating the perpetrator blame and job satisfaction relationship $\left(\mathrm{K}^{2}=.25\right)$. This suggests that when blame is attributed externally a dignity violation may occur, which can lead to negative work attitudes.

Insert Table 2 here 


\section{Discussion}

This study used dysempowerment theory and the attributional model of workplace harassment to investigate the impact of cyberbullying on trainee doctors. Results suggest that dysempowerment may occur even when an individual's dignity has not been violated as negative affect mediated the association between self-blame for cyberbullying and mental strain. This is consistent with past research indicating that the extent to which an individual blames themselves for traumatic events (e.g. rape, divorce) relates negatively to wellbeing ${ }^{42,43}$. These interactions could have occurred because doctors who believed they were at fault for experiencing cyberbullying may have reduced self-esteem by perceiving that they were responsible for the acts. For example, if a trainee doctor makes a mistake during work and is subsequently abused for that mistake via email, they may perceive that they have brought the abuse on themselves due to a lack of ability.

The impact cyberbullying exerted on job satisfaction was found to develop along a separate path to that of mental strain. Blaming the perpetrator for cyberbullying mediated the relationship between cyberbullying and interpersonal justice. This has theoretical implications as it suggests that a dignity violation may only occur when blame for a polluting event is attributed externally. Moreover, interactional injustice mediated the relationship between perpetrator directed attributions and job satisfaction, indicating that although trainee doctors who make external attributions for cyberbullying are possibly shielded from ill-health, an adverse effect is seen in their work attitudes.

\section{Practical Implications}

This study has implications for foundation doctor training. The relationship between selfblame, negative affect and mental strain demonstrates that individuals who tend to attribute blame internally are possibly more at risk of developing ill-health. NHS Trusts could therefore 
monitor individuals with a tendency to self-blame to prevent these unhelpful cognitions. In respect to the link between perpetrator blame, interactional injustice and job satisfaction, it has been suggested that more misunderstandings occur during online communication ${ }^{44}$, which may lead trainees to mistakenly perceive cyberbullying even when the sender meant no ill-intent. To prevent such misunderstandings, NHS policy ${ }^{45}$ encourages staff to think about whether electronic communication is appropriate for the matter they want to discuss. The policy also encourages health professionals to evaluate whether the tone of a correspondence could be misinterpreted by the recipient, as evidence suggests that people find emotion communicated through email difficult to interpret ${ }^{46}$.

Interestingly, the majority (31.7\%) of respondents cited other trainees as being mainly responsible for cyberbullying. This is a surprising finding given offline bullying research generally finds that supervisors and managers are the main perpetrators ${ }^{47}$. One possible explanation is that colleagues at the same occupational level take less care when communicating with each other through computer mediated communication, as Postmes, Spears and Lea ${ }^{48}$ found that emails sent to higher status individuals are more formal. Thus, emails sent to peers may appear rude in comparison, which could be misconstrued as bullying. Additionally, an estimated $90 \%$ of medical students use online social media ${ }^{49}$, which can be a platform for cyberbullying.

In response to the growing use of social media within the medical profession, it has been advised that professionals consider how online interactions could affect their career and the broader medical community ${ }^{50}$. In this respect, professionals are encouraged to think about their online interactions using the analogy of the "digital footprint", with each online action leaving a record and potential consequence. The American Medical Association has issued guidelines on the professional use of social media which includes advice on posting sensitive information, maintaining professional boundaries and privacy settings. Such information 
could be used to educate trainees and experienced medical professionals on how social media can be best integrated into their professional lives.

\section{Limitations and Future Research}

The study used a cross-sectional design which prohibits the investigation of causal processes between the study variables. In addition, the low response rate limits the generalisability of the findings as the sample may not be representative of the trainee doctor population. For instance, because participants were able to self-select their participation in the research, individuals who were not affected by cyberbullying may be underrepresented. However the low response rate does not negate the value of our findings as the study offers insights on the impact of cyberbullying among doctors who experience it. Future research needs to consider using multiple data sources and time points as this would enable a better understanding of the relationships between cyberbullying, emotion and health. Other researchers could also explore the behavioural outcomes of specific attributions and how these relate to theoretical understandings of coping strategies.

\section{Conclusion}

Advances in technology mean that health professionals are now required to be competent with computer systems, as well as technology mediated communication. Increased communication through technology mediated channels increases the potential for cyberbullying. The current study suggests that cyberbullying relates to job dissatisfaction and mental strain, however the impact is dependent on the way trainee doctors attributed blame for their experience. Given these initial findings, more research is needed to better understand the nature of cyberbullying and its impact in health care contexts. 
Figures and Tables

Figure 1: The Hypothesised Model

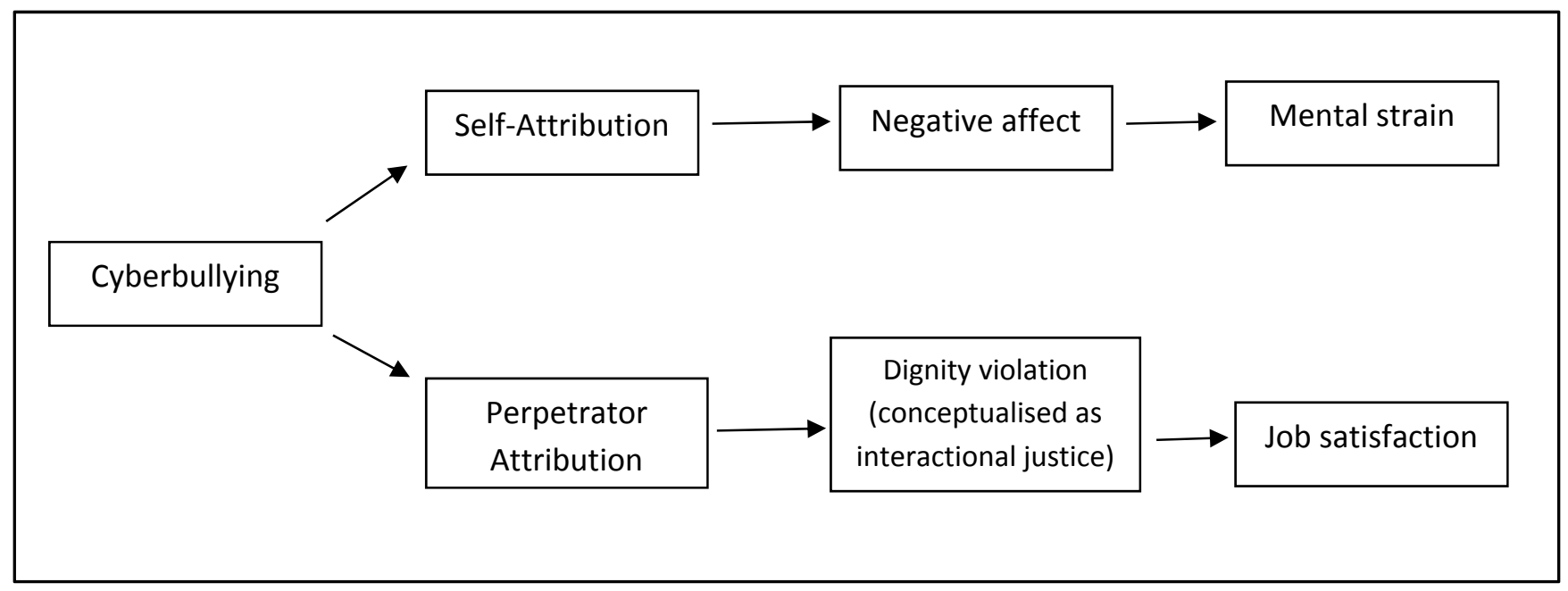

Table 1: Regression results of cyberbullying on mental strain and job satisfaction

$\begin{array}{llll}\text { Criteria and predictors } & \text { Adjusted R2 } & \text { R2 Change } & \beta\end{array}$

$F$ (d.f. 1, d.f.

2)

Mental strain

Model 1: Demographics $\quad .255^{* * *} \quad .270$

Model 2: Cyberbullying $\quad .294^{* * *} \quad .043^{* *}$

$216 \quad 16.49(4,145)$

Job satisfaction

Model 1: Demographics $\quad .190^{* * *} \quad .206$

Model 2: Cyberbullying .216* .031*

$-.185$

$12.55(3,145)$

$11.18(4,144)$

${ }^{*} p<0.05 ;{ }^{* *} p<0.01 ;{ }^{* * *} p<0.001$. Standardized betas presented for the final model. 


\begin{tabular}{|c|c|c|c|c|c|c|}
\hline IV & Mediator & Outcome & Point & \multicolumn{2}{|c|}{$\mathrm{BCa} 95 \% \mathrm{Cl}$} & $K^{2}$ \\
\hline \multicolumn{4}{|c|}{ Dysempowerment Relationships } & Lower & Upper & \\
\hline Cyberbullying & Negative affect & Mental strain & .0134 & .0050 & .0250 & .283 \\
\hline Cyberbullying & Negative affect & Job satisfaction & .0052 & -.0031 & .0194 & .041 \\
\hline Cyberbullying & $\begin{array}{l}\text { Interactional } \\
\text { justice }\end{array}$ & Job satisfaction & -.0200 & -.0372 & -.0066 & .191 \\
\hline Cyberbullying & $\begin{array}{l}\text { Interactional } \\
\text { justice }\end{array}$ & Mental strain & .0022 & -.0011 & .0073 & .108 \\
\hline \multicolumn{7}{|c|}{ Attribution Relationships } \\
\hline Cyberbullying & Self-blame & Negative affect & -.0035 & -.0129 & .0006 & .044 \\
\hline Self-blame & $\begin{array}{l}\text { Negative } \\
\text { affect }\end{array}$ & Mental strain & .0683 & .0236 & .1405 & .267 \\
\hline Cyberbullying & $\begin{array}{l}\text { Perpetrator } \\
\text { blame }\end{array}$ & $\begin{array}{l}\text { Interactional } \\
\text { justice }\end{array}$ & -.0154 & -.0355 & -.0042 & .073 \\
\hline $\begin{array}{l}\text { Perpetrator } \\
\text { attribution }\end{array}$ & $\begin{array}{l}\text { Interactional } \\
\text { justice }\end{array}$ & Job satisfaction & -.0958 & -.1789 & -.0384 & .248 \\
\hline
\end{tabular}


${ }^{1}$ The Japan Institute for Labour Policy and Training eds. Workplace Bullying and Harassment (12) 2013. JILPT Report 2013.

${ }^{2}$ Zapf D. 'Mobbing in Organisationen. Ein Überblick zum Stand der Forschung [Mobbing in organisations.A state of the art review]. Zeitschrift für Arbeits \& Organisations Psychologie 1999a;43: 1-25.

${ }^{3}$ Hubert AB, van Veldhoven M. Risk sectors for undesirable behaviour and mobbing. European Journal of Work and Organizational Psychology 2001;10: 415-424.

${ }^{4}$ General Medical Council eds. National Training Survey 2013: Undermining.GMC; 2013.

${ }^{5}$ Quine L. Workplace bullying in junior doctors: questionnaire survey. British Medical Journal 2002;324(7342): 878879.

${ }^{6}$ Payne KFB, Wharrad H, Watts K. Smartphone and medical related App use among medical students and junior doctors in the United Kingdom (UK): a regional survey. BMC Medical Informatics and Decision Making 2012;12(1): 121.

${ }^{7}$ Ling JM, Lim KZ, Ng WH. Use of Multimedia Messaging System (MMS) by Junior Doctors for Scan Image Transmission in Neurosurgery. World Neurosurgery 2012;77(2): 384-387.

${ }^{8}$ Baruch Y. Bullying on the net: Adverse behavior on e-mail and its impact. Information \& Management 2005;42(2): 361-371.

${ }^{9}$ Coyne I, Axtell C, Sprigg C, Farley S, Best L, Kwok O. Workplace cyberbullying, employee mental strain and job satisfaction: A dysempowerment perspective. Under Review: International Journal of Human Resource Management. 
${ }^{10}$ Smith PK, Mahdavi J, Carvalho M, Fisher S, Russell S, Tippett N. Cyberbullying: Its nature and impact in secondary school pupils. Journal of Child Psychology and Psychiatry 2008;49(4): 376-385.

${ }^{11}$ Slonje R, Smith PK. Cyberbullying: Another main type of bullying?. Scandinavian Journal of Psychology 2008;49(2): 147-154.

12 Tokunaga RS. Following you home from school: A critical review and synthesis of research on cyberbullying victimization. Computers in Human Behavior 2010;26(3): 277-287.

${ }^{13}$ Dooley JJ, Pyżalski J, Cross D. Cyberbullying versus face-to-face bullying. Zeitschrift für Psychologie/Journal of Psychology 2009;217(4): 182-188.

${ }^{14}$ Kane K, Montgomery K. A framework for understanding dysempowerment in organizations. Human Resource Management 1998;37: 263-275.

${ }^{15}$ Bowling NA, Beehr TA. Workplace harassment from the victim's perspective: a theoretical model and metaanalysis. Journal of Applied Psychology 2006;91(5): 998-1012.

${ }^{16}$ Frazier PA. Perceived control and distress following sexual assault: A longitudinal test of a new model. Journal of Personality and Social Psychology 2003;84: 1257-1269.

${ }^{17}$ Bowling NA, Michel JS. Why do you treat me badly? The role of attributions regarding the cause of abuse in subordinates' responses to abusive supervision. Work \& Stress 2011;25(4):309-320.

${ }^{18}$ Smith CA, Ellsworth PC. Patterns of appraisal and emotion related to taking an exam. Journal of Personality and Social Psychology 1987;52(3): 475-488.

${ }^{19}$ Brown J, Weiner B. Affective consequences of ability versus effort ascriptions: Controversies, resolutions, and quandaries. Journal of Educational Psychology 1984;76: 146-158. 
${ }^{20}$ Bies R, Moag J. Interactional justice: Communication criteria of fairness. In Lewicki RJ, Sheppard BH, Bazerman,

MH. Research on negotiations in organizations. 1st ed. Greenwich, CT: JAI Press; 1986. p43-55.

${ }^{21}$ Hershcovis MS, Barling J. Comparing victim attributions and outcomes for workplace aggression and sexual harassment. Journal of Applied Psychology 2010;95(5): 874-888.

${ }^{22}$ Tepper BJ. Consequences of abusive supervision. Academy of Management Journal 2000;43(2): 178-190.

${ }^{23}$ Davies H, Archer J, Southgate L, Norcini, J. Initial evaluation of the first year of the Foundation Assessment Programme. Medical Education 2009;43: 74-81.

${ }^{24}$ The Academy of Medical Royal Colleges eds. The foundation programme curriculum: July 2012.

${ }^{25}$ Privitera C, Campbell M. Cyberbullying: the new face of workplace bullying. CyberPsychology and Behavior 2009;12(4): 395-400.

${ }^{26}$ The UK Foundation Programme Office eds. The foundation programme annual report 2012: Report No. 4 January 2013.

${ }^{27}$ Einarsen S, Hoel H, Notelaers G. Measuring exposure to bullying and harassment at work: Validity, factor structure and psychometric properties of the Negative Acts Questionnaire-Revised. Work and Stress 2009;23: 2444.

${ }^{28}$ Groth M, Goldman BM, Gilliland SW, Bies RJ. Commitment to legal claiming: Influences of attributions, social guidance, and organizational tenure. Journal of Applied Psychology 2002;87(4): 781-788.

${ }^{29}$ Watson D, Clark LA, Tellegen A. Development and validation of brief measures of positive and negative affect: The PANAS scale. Journal of Personality and Social Psychology 1988;54: 1063-1070. 
${ }^{30}$ Bowling NA, Beehr TA, Bennett, MM, Watson CP. Target personality and workplace victimization: A prospective analysis. Work \& Stress 2010:24(2): 140-158.

${ }^{31}$ Scarpello V, Campbell JP. Job Satisfaction: Are All the Parts There? Personnel Psychology 1983;36(3):577-600.

${ }^{32}$ Ganzach Y. Intelligence and job satisfaction, Academy of Management Journal 1998;41(5): 526-539.

${ }^{33}$ Goldberg DP, Williams P. The User's Guide to the General Health Questionnaire. Windsor: NFER-Nelson; 1988.

${ }^{34}$ Stanton JM, Balzer WK, Smith PC, Parra LF, Ironson G. A General Measure of Work Stress: The Stress in General Scale. Educational and Psychological Measurement 2001;61(5): 866-888.

35 Jamieson S. Likert scales: How to (ab)use them. Medical Education 2004;38:1217-1218.

${ }^{36}$ Pearson ES. The analysis of variance in the case of non-normal variation. Biometrika 1931;23:114-133.

${ }^{37}$ Hayes AF. Beyond Baron and Kenny: Statistical mediation analysis in the new millennium. Communication Monographs 2009;76(4): 408-420.

${ }^{38}$ Baron RM, Kenny DA. The moderator-mediator variable distinction in social psychological research: conceptual, strategic, and statistical considerations. Journal of Personality and Social Psychology 1986;51(6):1173-82.

${ }^{39}$ Sobel M. Some new results on indirect effects and their standard errors in covariance structure models. In N. Tuma (eds) Sociological Methodology. Washington, DC: American Sociological Association 1986. p159-186.

${ }^{40}$ Preacher KJ, Hayes AF. Asymptotic and resampling strategies for assessing and comparing indirect effects in multiple mediator models. Behavior Research Methods 2008;40(3): 879-891. 
${ }^{41}$ Preacher KJ, Kelley K. Effect size measures for mediation models: quantitative strategies for communicating indirect effects. Psychological Methods 2011;16(2), 93.

42 Frazier PA. Victim attributions and post-rape trauma. Journal of Personality and Social Psychology 1990;59: 298304.

${ }^{43}$ Healy JM, Stewart AJ, Copeland AP. The role of self-blame in children's adjustment to parental separation. Personality and Social Psychology Bulletin 1993:19: 279-289.

${ }^{44}$ Byron K. Carrying too heavy a load? The communication and miscommunication of emotion by email. Academy of Management Review 2008;33(2): 309-327.

${ }^{45}$ The National Health Service Commissioning Board: Respect in the workplace policy 2012 Version 1.

${ }^{46}$ Byron K, Baldridge D. Toward a model of nonverbal cues and emotion in email. In KM Weaver (Ed.), Academy of Management Best Papers Proceedings 2005 OCIS B1- B6.

${ }^{47}$ Hoel H, Faragher B, Cooper CL. Bullying is detrimental to health, but all bullying behaviours are not necessarily equally damaging. British Journal of Guidance and Counselling 2004;32: 367-387.

${ }^{48}$ Postmes T, Spears R, Lea, M. The formation of group norms in computer mediated communication. Human Communication Research 2000;26: 341-371.

${ }^{49}$ Bosslet G, Torke A, Hickman S, Terry C, Helft P. The patient-doctor relationship and online social networks: Results of a national survey. Journal of General Internal Medicine 2011;26:1-7.

${ }^{50}$ Greysen SR, Kind T, Chretien KC. Online Professionalism and the Mirror of Social Media. Journal of General Internal Medicine 2010;25(11):1227-1229. 